\title{
A INFLUÊNCIA DO FENÔMENO EL NIÑO NA PRODUÇÃO DA SOJA NO MUNICÍPIO DE CAMPO MOURÃO
}

\author{
Jeremias Alecio Leperes de Marins $^{\left({ }^{a}\right)}$, Nair Gloria Massoquim ${ }^{\text {(b) }}$ \\ (a) Mestrando em Geografia. Universidade Estadual do Oeste do Paraná, Câmpus de Marachal Candido Rondon, \\ jaleciomarins@hotmail.com \\ (b) Colegiado de Geografia. Universidade Estadual do Paraná (UNESPAR), Câmpus de Campo Mourão, \\ nmassoquim@gmail.com
}

\section{Eixo: CLIMATOLOGIA EM DIFERENTES NÍVEIS ESCALARES: MUDANÇAS E VARIABILIDADES}

\begin{abstract}
Resumo
O Município de Campo Mourão, localizado na Mesorregião Centro Ocidental Paranaense tem na produção agrícola a principal fonte econômica. No aspecto geológico é composto de rochas basálticas, solos rico em argila e topografia plana a suave ondulada propícia a culturas mecanizadas, especialmente da soja. O Clima é Subtropical do tipo Cfb, em transição para Cfa (ITCG, 2006), contudo, esse fator positivo, nos anos de variação climáticas, especialmente dos ENOS, traz anomalias que altera a dinâmica da paisagem agrícola, resultando em uma baixa produtividade. Neste sentido, o objetivo dessa pesquisa é analisar a influência e interferência do fenômeno El Niño, na produtividade agrícola das culturas comerciais, de importância fundamental na economia do município. No desenvolvimento da pesquisa utilizou-se de referencial teórico, pesquisa de campo, coleta de dados, confecção e análise de tabelas e gráficos. Resultados climáticos indicam que o El Niño é um fenômeno de interferência na dinâmica da paisagem agrícola.
\end{abstract}

Palavras-chave: Clima; Paisagem; Precipitação pluviométrica.

\section{Introdução}

O clima é um elemento que tem forte influência na evolução da paisagem, por ser ao mesmo tempo um agente condicionante e agravante na sua dinâmica (MASSOQUIM, 2010). Neste sentido pode-se dizer que o clima é um dos fatores primordiais para o desenvolvimento da paisagem agricola, demonstrado na produção e produtividade dos cultivares. O processo na dinâmica da paisagem são consequencia dos elementos físicos, biológicos e antrópicos, em um determinado lugar, que resulta numa constante transformação, e a agricultura esta incluida neste contexto (MARINS, MASOQUIM e BORSATO, 2016).

O Município de Campo Mourão, em razão da sua relevância na produção agrícola como principal fonte econômica é destaque na paisagem regional. Considerando ainda os aspectos geoecológicos, possui uma estrutura geológica composta de rochas basálticas e formação de um solo profundo e rico em argila, como uma topografia que lhe confere a maior proporção (cerca de $80 \%$ ) da área em relevos planos a suave ondulados, propício ao desenvolvimento de culturas agrícolas mecanizadas (MASSOQUIM, 2010). 
Outro fator relevante é o clima, considerado do grupo Subtropical úmido, do tipo $\mathrm{Cfb}$, transição para Cfa (SIMEPAR/ITCG, 2006) é considerado como atributo de forte influência no desenvolvimento da produção agrícola. Contudo, nos anos de variação climáticas do ENOS e de La Niña, temos anomalias que resultam em baixa na produtividade das culturas agrícolas. Culturas estas, de importância fundamental na economia do município, estudos dessa natureza precisam ser consolidados, por meio de planejamento, visando informações de quebras ou não na produção agrícola e da influência na dinâmica dessa paisagem.

No caso do município de Campo Mourão, que está localizado a 68 km ao Sul do trópico de Capricórnio e compreende a região climática subtropical, caracterizada como zona subtropical úmida, e influenciada pelas massas de ar Polar Atlântica, Tropical Atlântica, Tropical Continental e Equatorial Continental, pode-se dizer que posui local previlegiado quando a dinamica climatica.

De acordo com Borsato (2013), estas massas de ar se categorizam por diferentes padrões sendo que as continentais são sistemas de baixa pressão e as oceanicas de alta pressão. Elas se diferem da normalidade já que a massa Tropical continental mesmo sendo de baixa pressão tem umidade relativamente baixa. Já a massa Tropical atlântica mesmo sendo um sistema de alta pressão tem caracteristica umida.

As massas de ar atuam como reguladoras dos tipos de tempo e de fenômenos como o ENOS que em contrapartida modifica o padrão atmosferico em período de forte atuação (La Niña/El Niño) resultando no aumento ou redução de precipitação e temperatura (MASSOQUIM, 2010). O fenômeno El Niño provocada a variação de pressão atmosférica, devido a mudança da temperatura do oceano pacifico equatorial, podendo resultar em mudança na circulação da atmosfera global (AMBRIZZI, 2003).Nos episódios anormais, caracterizados por fenômenos adversos, como o El Niño ou a La Niña, o munícipio de Campo Mourão tende a sofrer com perdas na produtividade agrícola (MASSOQUIM e AZEVEDO, 2010). Neste sentido deve ser discutida a relação clima e agricultura, junto à variabilidade climática, considerando a dinâmica da atmosfera e a interação com os oceanos.

\section{Metodologia}

Para o desenvolvimento da pesquisa utilizamos de procedimentos operacionais a partir de leituras e fichamentos bibliograficos com temáticas sobre: clima, variabilidade climática e agricultura de Campo Mourão. Também foram lidos textos e coletado dados nos sites: NOAA e CPTEC/INPE, que abordam a tematica dos ENOS. Para análise foram realizadas as médias climatológicas dos dados de precipitação pluviométrica mensal, de 52 anos de dados (1963 a 2014) obtida no Banco de Dados Meteorológicos para Ensino e Pesquisa (BDMEP) do INMET (Instituto Nacional de Meteorologia).

As médias obtidas dos dados foram tabuladas por meio do Microsoft Excel, e relacionadascom dados de 2015 e 2016 (período de atuação do El Niño), além da análise e interpretação das médias de temperatura 


\section{OS DESAFIOS DA GEOGRAFIA FÍSICA NA FRONTEIRA DO CONHECIMENTO \\ Instituto de Geociências - Unicamp \\ Campinas - SP \\ 28 de Junho à 02 de Julho de 2017}

mínima. A partir disso foram analisados os meses de maior acumulado, sendo eles julho e novembro de 2015, fevereiro e maio de 2016. Para melhor compreensão da atuação dos fenômenos foram observadas as cartas sinóticas obtidas pelo site da marinha, verificando-se as massas de ar e os sistemas frontais mais atuantes, durante o período de maior acumulo pluviométrico, presumindo o tipo de massa (BORSATO e MENDONÇA, 2013).

\section{Resultados}

Analisado-se os dados dos anos de 2015/2016 (NOAA, 2016), obsevou-se que esses anos foram atingidos por um forte El Niño, que teve sua configuração no final do ano de 2014, mas efetivamente teve seu início em meados do mês de março de 2015. Porém, pudemos perceber anomalias na precipitação a partir do mês de julho de 2015, sendo este considerado o mais chuvoso dentre os 52 anos de coleta de dados (INMET, 2015), a quantidade de precipitação em julho de 2015 foi de 477,1 sendo mais do que o dobro da maior precipitação pluviométrica já registrada durante este mês, desde o ano de 1963. Demostrando dessa forma que a atuação dos ENOS tem forte influência da variabilidade pluviométrica, gráfico 1.

De acordo com os dados de precipitação pluviométrica (INMET), o município de Campo Mourão tem uma media anual de $1675 \mathrm{~mm}$. Contudo, nesta pesquisa observamos que no ano de 2015 o volume de pluviométrico registrado foi de $2803,4 \mathrm{~mm}$. Este foi o ano com o maior volume pluviométrico já registrado, superando o de 2526,2 mm, registrado no ano de 1983 (INMET) ano que também esteve sobre influência do fenômeno El Niño. Quanto à temperatura média para Campo Mourão, de acordo com os dados do INMET esteve em torno de $21,1^{\circ} \mathrm{C}$, a média da máxima em $27^{\circ} \mathrm{C}$ e da mínima $15,2^{\circ} \mathrm{C}$. Durante o período do El Niño (2015/2016) a temperatura média mínima ficou em torno de $16,9^{\circ}$, sendo assim $1,7^{\circ}$ acima da média normal, (durante o periodo não houve registro de temperatura máxima pelo INMET).

Já, ao analisar o gráfico 2, temos os meses de influência do El Niño sendo de março de 2015 a maio de 2016, nos quais foram observados que os maiores valores pluviométricos foram registrados nos meses de julho e novembro de 2015 e, fevereiro e maio de 2016. Sendo que o período de atuação foi registrado de março de 2015 a maio de 2016, atingindo período de plantio tanto do milho safrinha quanto da soja.

O período de maior valor pluviométrico ocorreu dentre os meses de outubro a fevereiro, e neste período é cultivado a safra de verão, sendo composta em especial pelo cultivo da soja, que nos anos anteriores tem ocupado mais de $60 \%$ da área do município de Campo Mourão, apesar dos dados de produtividade neste período (2015/2016) ainda não serem divulgados, podemos presupor quebra na produtividade da soja, devido ao alto pluviométrico durante o mês de novembro. 


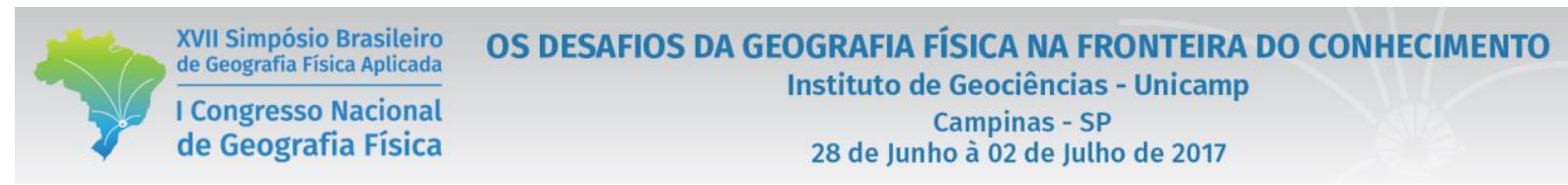

Durante o ano de 2015 os maiores valores pluviométricos foram registrados em julho e novembro, sendo que no mês de novembro e dezembro a TSM sofreu maior anomalia positiva. Já em janeiro de 2016, ápice do El Niño, a precipitação ficou abaixo da normalidade, o que não ocorreu em fevereiro em que a chuva foi acima da média dificultando a colheita e procando quebra na produtividade em relação à 2014/2 015.

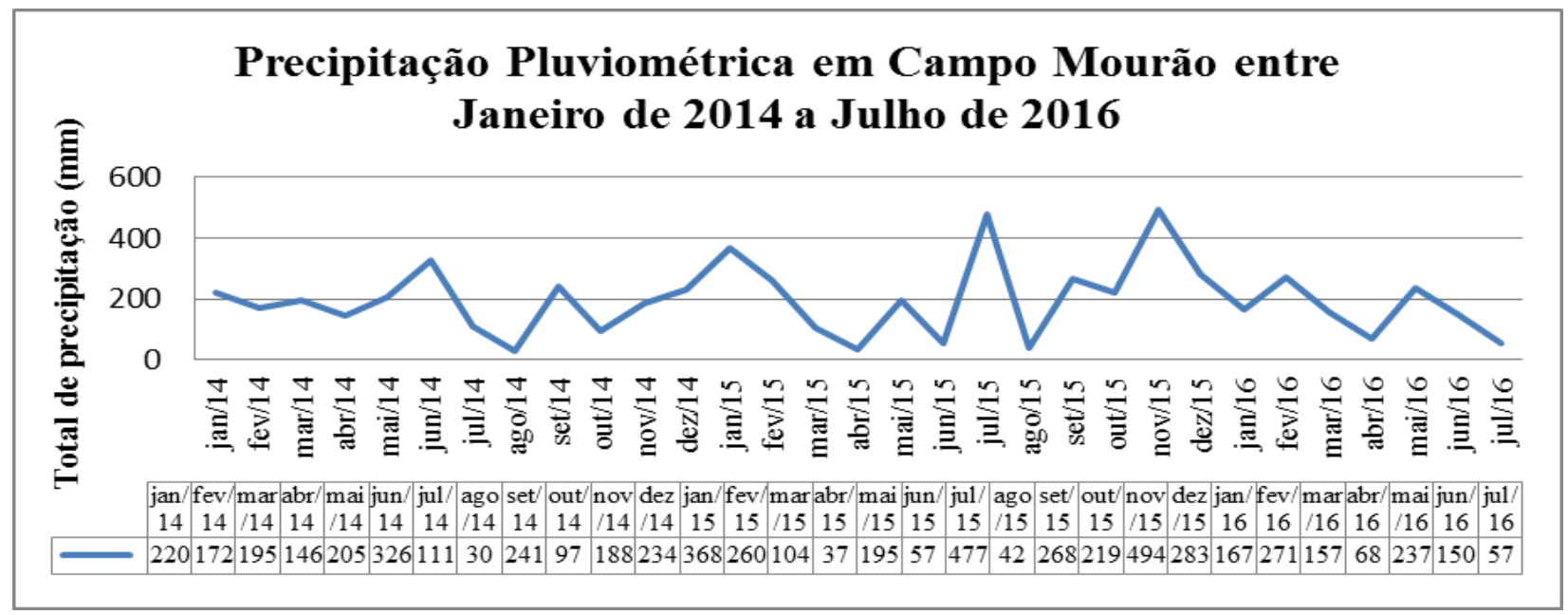

Gráfico 1 - Estações Meteorológicas de coleta de dados

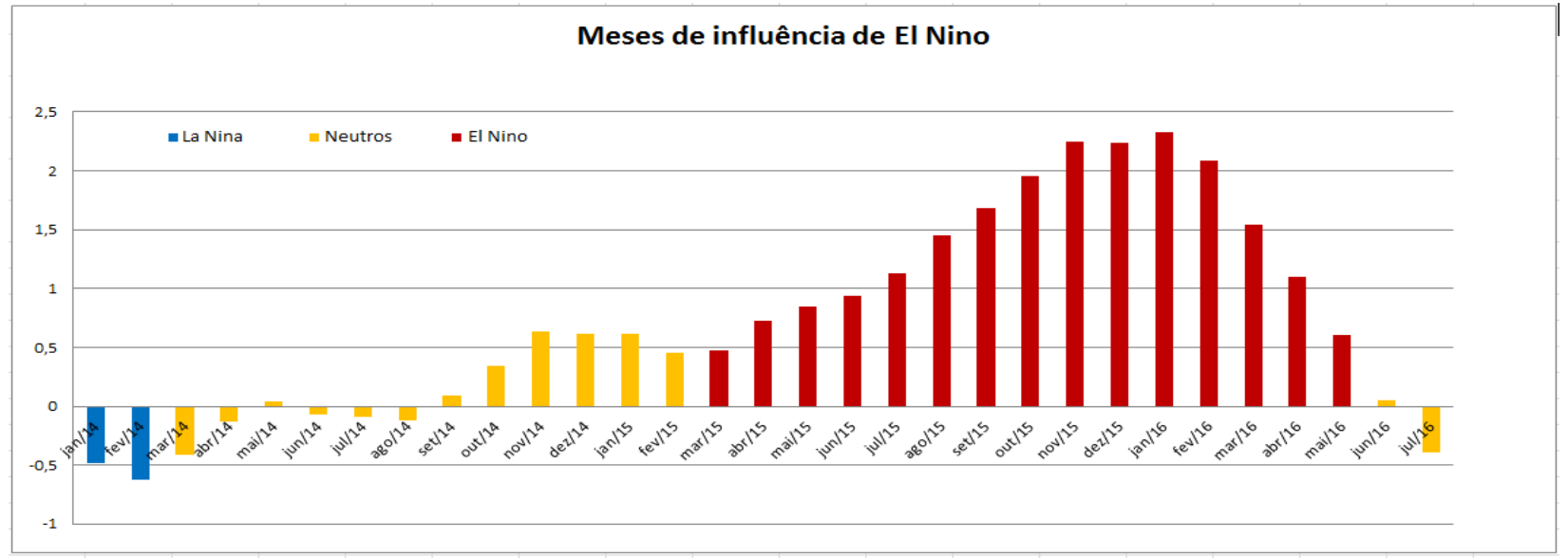

Gráfico 2 - Atuação dos ENOS dos anos de 2015 e 2016

\section{Considerações}

Constatamos que esse foi um dos El Niño mais chuvosos dos ultimos 40 anos. Conforme foi mostrado no gráfico 2, o período durou 14 meses, de março de 2015 a maio de 2016. Observamos que a safra 2014/2015 não foi afetada, já que fevereiro a início de março são períodos de colheita e o El Niño estava na fase inicial. Já no caso da safra de 2015/2016, foi afetada no seu processo fenológico e na fase de colheita pelo excesso de chuvas. A maior quantidade de precipitação ocorreu em novembro, período em que a soja ainda não estava num significativo crescimento fenológico para que ouvesse o acamamento, outro fator positivo para a mesma e o de que os tipos de variedades foram mudando conforme a 


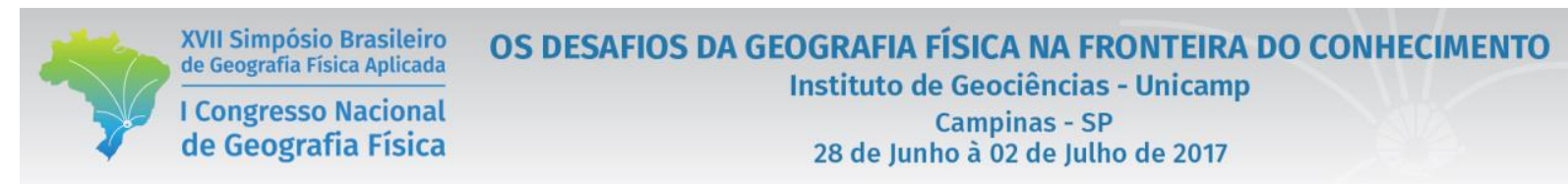

necessidade regional, hoje planta-se variedades com um menor volume da rama (pés da soja) para que o excesso de chuva não provoque o acamamento, dificultando sua colheita. Diante disso podemos concluir que houve quebra na produtividade na safra 2015/2016, provocada pelo volume de chuva, e umidade excessiva no mês de fevereiro de 2016, sendo consecutivamete o período de colheita.

Ademais, observamos nas cartas sinóticas que durante o período analisado, ouve atuação dos sistemas frontais e do jato de baixos níveis (que traz umidade da região da Amazônia), maior atuação do sistema de baixa pressão do Chaco com a mTc, associada à $\mathrm{mEc}$, (confluência ou não da $\mathrm{mPa}$ ), que contribuíram para a expressiva pluviometria, aguaceiros que em alguns episódios superaram a $100 \mathrm{~mm}$ em 24 horas.

\section{Bibliografia}

AMBRIZZI, Tércio. El Niño/Oscilação Sul e teleconexões atmosféricas no hemisfério austral. 2003. $201 \mathrm{f}$. Tese (Livre-Docência). IAG, Universidade de São Paulo, São Paulo. 2003.

BORSATO, Victor da Assunção; MENDONÇA, Francisco de Assis. A dinâmica dos sistemas atmosféricos no verão 2012-2013 no Paraná e em Campo Mourão. In: Simpósio Nacional de Estudos Urbanos, 2., 2013, Campo Mourão. Anais eletrônicos... Campo Mourão: UNESPAR campus de Campo Mourão, 2013. Disponível em: $\langle$ http://www.fecilcam.br/anais/ii_seurb/documentos/questao-ambiental-urbana/borsato-victor-da-assuncao.pdf >. Acessado em: 13 dez. 2016.

INSTITUTO DE TERRAS, CARTOGRAFIA E GEOCIÊNCIAS. Clima: Estado do Paraná. Disponível em:<http://www.itcg.pr.gov.br/arquivos/File/Produtos_DGEO/Mapas_ITCG/PDF/Mapa_Climas_A3.pdf>. Acessado em: 10 dez. 2016.

INSTITUTO NACIONAL DE METEOROLOGIA. Banco de Dados Meteorológicos para Ensino e Pesquisa. Disponível em: <http://www.inmet.gov.br/portal/index.php?r=bdmep/bdmep>. Acessado em: 10 dez. 2016.

MARINS, Jeremias Alecio Leperes de; MASSOQUIM, Nair Glória; BORSATO, Victor da Assunção. A influência do clima na dinâmica da paisagem agrícola na região de Campo Mourão - Pr. entre os anos de 2005 a 14. In: Simpósio Brasileiro de Climatologia Geográfica, 12., 2016, Goiânia. Anais eletrônicos... Goiânia: UFG, 2016. Disponível em: <http://www.abclima.ggf.br/sbcg16/anais/arquivos/eixo_4/trabalho\%20(2).pdf>. Acesso em $10 \mathrm{dez}$. 2016.

MASSOQUIM, Nair Gloria. AZEVEDO, Tarik Rezende. interferência de fenômenos climáticos em culturas temporárias na microrregião de campo mourão. Revista GEOMAE, 2010.

MASSOQUIM, Nair Gloria. Clima e Paisagem na Mesorregião Centro Ocidental Paranaense. 2010. 398 f. Tese (Doutorado em Geografia) - Faculdade de Filosofia, Letras e Ciências Humanas, Universidade de São Paulo, São Paulo. 2010.

NATIONAL OCEANIC \& ATMOSPHERIC ADMINISTRATION. Historical EI Nino/ La Nina episodes (1950present). Disponível em: <http://www.cpc.ncep.noaa.gov/products/analysis_monitoring/ensostuff/ensoyears2011.shtml>. Acessado em: 17 dez. 2016 